\title{
An Analysis of English Language Orthography, Typography and Grammar used by Millennial on Social Media Platforms
}

\author{
Alia Khan \\ Ph.D. Research Scholar \\ Department of English \\ Aligarh Muslim University \\ Aligarh, Uttar Pradesh, India \\ aliakhan202@gmail.com
}

Prof. Mohammad Rizwan Khan

Professor and Chairman

Department of English

Aligarh Muslim University

Aligarh, Uttar Pradesh, India

\begin{abstract}
Social media is a term with which most of the people around the world are well acquainted. The advancement of technology has provided a new medium through which we can propose, deliver, swap, and share our ideas without moving a single inch. It is a new avenue for conveying information and a trend which is now-a-days in vogue. From infants to adults, everyone is somehow in contact with the social media. Similarly, education system too has a profound influence of social media. From placement institutes, school authority, teachers, learners, to parents in fact every stakeholder of education system is somehow tied to social media. Jeff Bezos, CEO at Amazon.com once described the power of social media by asserting
\end{abstract}


that "If you make customers unhappy in the physical world, they might each tell 6 friends. If you make customers unhappy on the Internet, they can each tell 6,000 friends" (Pencak 2019). Thus, we can assume the potency and status of social media in our life. Though social media is affecting many significant areas of human life, but the area which itself is considered as a 'systematic means of communication' (that is 'Language') is too being swayed by this virtual medium. Social media has exceedingly affected English language skills. The paper explores how the social media has influenced linguistics habits of millennial, whether it has affected upcoming academicians in a positive or negative way, and what should be done in order to protect their linguistic habits from the negative influence of social media.

Keywords: Textese, Textism, WhatsApp, Instagram, Facebook, Language, Social media

Introduction

Social media has now become an old forum for communication and socialization. It has turn out to be people's integrated part of life. Every bits of our life is somehow connected to social media and this is best described by David Crystal as:

You wake up at 3 a.m. to go to the bathroom and stop to check your e-mail on the way back to bed. You sign off and your screen says you were on 3 days and 45 minute. You placed the refrigerator beside your computer. You say 'scroll up' when someone asks what it was you said. All of your friends have an @ in their names. You tell the cab driver you live at http://123.elm.street/house/bluetrim.html.Your phone bill comes to your doorstep in a box. You check your mail. It says 'no new messages'. So you check it again. (1-2)

Here is the statistic that shows how much the world is involved in social media. "Social media has become part of the furniture, spanning all generations and all walks of life. It is estimated 
that 2.77 billion of us will be using social media by the end of 2019" (Ormerod 2018). "Facebook is now, by a very wide margin, the biggest social network worldwide. As of the fourth quarter of 2020, Facebook had more than 2.8 billion global monthly active users" (Tankovska 2021). In the fourth quarter of 2020, Twitter had 330 million monthly active users; YouTube is one of the platforms which is in trend and as of the fourth quarter of 2018, 27 percent of internet users worldwide accessed YouTube at least once per day and in 2019 the YouTube recorded 1.68 billion users. In June 2018, Instagram reported more than 1 billion monthly active users worldwide and its daily active users stood at 500 million; Tumblr had surpassed 472 million registered accounts in July 2019; WhatsApp had 1.6 billion monthly active users worldwide in 2019, and during the fourth quarter of 2019 Snapchat reported 218 million daily active users worldwide. Apart from these platforms, numerous social media apps are available with their millions of users ("Twitter": 2021; "YouTube": 2021; Clement: 2020; “Tumblr": 2019; “WhatsApp": 2019; "Snapchat”: 2021).

Through the mentioned statistic it is understood that social media trend is not only the tale of one nation but of the whole world. In our life the role of social media is crucial; it is not an appendage extra but an indispensable part of our daily routine. It has affected every spheres of our life and one of the significant spheres that are being affected by the influence of social media is our language. Whether it is mother tongue (here in India it is Hindi) or our second language (English), both are deeply affected by the inclusion of social media in our lives.

Before exploring the objectives of this paper, it is necessary to understand what exactly Social Media is and how it has affected the major channel of communication (i.e. Language). People considered social media only in term of apps that are in vogue like Facebook, WhatsApp, and Instagram, but social media is an umbrella term and include lots of other platforms. Jagtap and Khare untangled the term social media by mentioning Heidi Cohen's explanation of features of social media. According to Cohen, social media is the medium 
through which people participate, comment and create content for communicating with their social contacts and public and hence turn the web into an interactive platform. She has mentioned certain features of social media, they are as follows: One can share content of different formats like text, video, photograph, audio, PDF and PowerPoint; interaction can cross different platforms through social sharing, email, etc.; participants can involve themselves as they want: there is no restriction in terms of involvement level, they can create, share, comment, lurk on social media networks as per their wish; information can be shared at a high speed and in large amount; one can communicate at different levels like one-to-one, oneto-many, many-to-many; communication can take place synchronously (online) and asynchronously (offline, not as per the time); it can work on various devices apart from computer like laptop, notebook, tablets (that includes iPads, iTouch and others), mobile phones (specially Smartphone); earlier real time events that is live event used to happen face-to-face (physical presence was must) but now because of social media one can engage in real time event by appearing online and can express his/her view point. According to Andreas Kaplan and Michael Henlein Social Media is, "a group of internet-based applications that build on ideological and technological foundations of web 2.0 and that allow the creation and exchange of user-generated content" (qtd. in Jagtap and Khare 2013: 1060-1061). While Techopedia website defines social media as:

Social media is perceived as a Web 2.0 development, which is to say that it is founded on the concept of a user-driven, interactive web. Blogs, message boards and chat rooms provide an experience that could be described as social media, but the term is more strongly identified with sites like Twitter, Facebook, Digg, LinkedIn, and so on. Like many buzzwords, the meaning of social media is a moving target that gets shifted around according to what the person using it wants it to mean. ("Social Media" 2019) 
In all these expression and sharing of views and contents, one aspect plays a significant role. It not only connects user of various platforms of social media and but also enables people to put their views in the form of text and that aspect is Language. But the language most people adhere to on social media is Textese. "In such language, standard spelling conventions and grammar rules are often disregarded and the use of "textisms" is prevalent" (Verheijen 2013: 583). Verheijen has mentioned Time, Space, Money and Trends are the significant reason behind the use of textism on social media platforms. In order to save time, space and money people are sticking to this "orthographically unconventional language". In addition to these factors, one more factor Verheijen (2019) has emphasized is the fashion to flaunt or fashion to follow trends. Millennial craves to look cool in every aspect of their life. So in order to look cool they follow textisms (583). Up till now, many studies have taken place in order to see the effect of Textism on literacy. But, there is mixed response regarding the effect of Textisms on language skills of the millennial. Verheijen has mentioned that, "the mixed results could also be caused by differences in the designs and populations of the studies. In addition, the correlational analyses conducted in most of the studies do not warrant conclusions about causality. All this suggests that there is a need for further research"(582). Here is the glimpse of the Empirical studies on the effect of Social Media on Language learning: 


\begin{tabular}{|c|c|c|c|c|c|c|c|}
\hline $\begin{array}{l}\text { Year of } \\
\text { publication }\end{array}$ & Author(s) & Focus & $\begin{array}{l}\text { Participants' age group } \\
\text { (age range/mean age) }\end{array}$ & $\begin{array}{l}\text { Participants' } \\
\text { nationality }\end{array}$ & $\begin{array}{l}\text { Sample size } \\
\text { (no. of } \\
\text { participants) }\end{array}$ & What aspect(s) of literacy? & Findings \\
\hline 2007 & $\begin{array}{l}\text { Massengill Shaw, } \\
\text { Carlson and } \\
\text { Waxman }\end{array}$ & texting & young adults (18-19) & American & 86 & spelling & no correlation \\
\hline 2008 & $\begin{array}{l}\text { Plester, Wood and } \\
\text { Bell }\end{array}$ & texting & children (10-12) & British & 100 & writing, spelling & $\begin{array}{r}\text { conflicting } \\
\text { findings }\end{array}$ \\
\hline \multirow[t]{3}{*}{2009} & Drouin and Davis & texting & $\begin{array}{l}\text { young adults ( } M \text { age }= \\
22 \text { ) }\end{array}$ & American & 80 & $\begin{array}{l}\text { reading (fluency and word } \\
\text { recognition), spelling }\end{array}$ & $\begin{array}{r}\text { conflicting } \\
\text { findings }\end{array}$ \\
\hline & $\begin{array}{l}\text { Plester, Wood and } \\
\text { Joshi }\end{array}$ & texting & children (10-12) & British & 88 & $\begin{array}{l}\text { reading, spelling, vocabulary, } \\
\text { non-word reading (alphabetic } \\
\text { decoding), phonological } \\
\text { awareness }\end{array}$ & $\begin{array}{l}\text { positive } \\
\text { correlation }\end{array}$ \\
\hline & $\begin{array}{l}\text { Winzker, Southwood } \\
\text { and Huddlestone }\end{array}$ & $\begin{array}{l}\text { texting, } \\
\text { IMing }\end{array}$ & $\begin{array}{l}\text { adolescents (grades } 8 \text {, } \\
11 \text {, age range/mean } \\
\text { age unspecified) }\end{array}$ & South African & 88 & writing, spelling & $\begin{array}{r}\text { conflicting } \\
\text { findings }\end{array}$ \\
\hline \multirow[t]{4}{*}{2010} & Kemp & texting & $\begin{array}{l}\text { young adults ( } M \text { age = } \\
22 \text { ) }\end{array}$ & Australian & 61 & $\begin{array}{l}\text { reading, spelling, morphological } \\
\text { awareness, phonological } \\
\text { awareness }\end{array}$ & $\begin{array}{l}\text { positive } \\
\text { correlation }\end{array}$ \\
\hline & Rosen et al. & $\begin{array}{l}\text { texting, } \\
\text { IMing }\end{array}$ & young adults (18-25) & American & 718 & writing & $\begin{array}{l}\text { conflicting } \\
\text { findings }\end{array}$ \\
\hline & $\begin{array}{l}\text { Shafie, Darus and } \\
\text { Osman }\end{array}$ & texting & young adults (18-22) & Malaysian & 264 & writing, spelling & $\begin{array}{l}\text { conflicting } \\
\text { findings }\end{array}$ \\
\hline & Varnhagen et al. & IMing & adolescents (12-17) & Canadian & 40 & spelling & no correlation \\
\hline 2011 & $\begin{array}{l}\text { Bushnell, Kemp and } \\
\text { Martin }\end{array}$ & texting & children (10-12) & Australian & 227 & spelling & $\begin{array}{l}\text { positive } \\
\text { correlation }\end{array}$ \\
\hline
\end{tabular}

\begin{tabular}{|c|c|c|c|c|c|c|c|}
\hline $\begin{array}{l}\text { Year of } \\
\text { publication }\end{array}$ & Author(s) & Focus & $\begin{array}{l}\text { Participants' age group } \\
\text { (age range/mean age) }\end{array}$ & $\begin{array}{l}\text { Participants' } \\
\text { nationality }\end{array}$ & $\begin{array}{l}\text { Sample size } \\
\text { (no. of } \\
\text { participants) }\end{array}$ & What aspect(s) of literacy? & Findings \\
\hline & Drouin & texting & $\begin{array}{l}\text { young adults ( } M \text { age }= \\
21 \text { ) }\end{array}$ & American & 152 & $\begin{array}{l}\text { reading (fluency and accuracy), } \\
\text { spelling }\end{array}$ & $\begin{array}{l}\text { conflicting } \\
\text { findings }\end{array}$ \\
\hline & $\begin{array}{l}\text { Durkin, Conti- } \\
\text { Ramsden and } \\
\text { Walker }\end{array}$ & texting & late adolescents (17) & British & 94 & $\begin{array}{l}\text { reading (efficiency and accuracy), } \\
\text { spelling }\end{array}$ & $\begin{array}{l}\text { positive } \\
\text { correlation }\end{array}$ \\
\hline & $\begin{array}{l}\text { Geertsema, Hyman } \\
\text { and Van Deventer }\end{array}$ & $\begin{array}{l}\text { texting, } \\
\text { IMing }\end{array}$ & $\begin{array}{l}\text { adolescents (grades } 8 \text {, } \\
9 \text {, age range/mean } \\
\text { are unspecified) }\end{array}$ & South-African & 22 (teachers!) & writing, spelling & $\begin{array}{l}\text { negative } \\
\text { correlation }\end{array}$ \\
\hline & Kemp and Bushnell & texting & children (10-12) & Australian & 86 & $\begin{array}{l}\text { writing, reading (speed and } \\
\text { accuracy), non-word reading, } \\
\text { spelling }\end{array}$ & $\begin{array}{l}\text { positive } \\
\text { correlation }\end{array}$ \\
\hline & Powell and Dixon & texting & $\begin{array}{l}\text { young adults ( } M \text { age }= \\
24)\end{array}$ & British & 94 & spelling & $\begin{array}{l}\text { positive } \\
\text { correlation }\end{array}$ \\
\hline & $\begin{array}{l}\text { Wood, Jackson, Hart, } \\
\text { Plester and Wilde }\end{array}$ & texting & children $(9-10)$ & British & 114 & $\begin{array}{l}\text { reading, spelling, non-word } \\
\text { reading (phonological } \\
\text { decoding), phonological } \\
\text { awareness, phonological } \\
\text { retrieval, lexical retrieval }\end{array}$ & $\begin{array}{l}\text { conflicting } \\
\text { findings }\end{array}$ \\
\hline & $\begin{array}{l}\text { Wood, Meachem, } \\
\text { Bowyer, Jackson, } \\
\text { Tarczynski-Bowles } \\
\text { and Plester }\end{array}$ & texting & children (8-12) & British & 119 & $\begin{array}{l}\text { reading, spelling, phonological } \\
\text { awareness, phonological } \\
\text { retrieval }\end{array}$ & $\begin{array}{l}\text { positive } \\
\text { correlation }\end{array}$ \\
\hline 2012 & De Jonge and Kemp & texting & $\begin{array}{l}\text { adolescents (13-15); } \\
\text { young adults } \\
\text { (18-24) }\end{array}$ & Australian & $52 / 53$ & $\begin{array}{l}\text { reading, non-word reading } \\
\text { (phonological decoding), } \\
\text { spelling, morphological } \\
\text { awareness, orthographic } \\
\text { awareness }\end{array}$ & $\begin{array}{l}\text { negative } \\
\text { correlation }\end{array}$ \\
\hline
\end{tabular}

Figure 1: The summary of Empirical studies on the Effect of Social Media on Language by

Verheijen (2013: 601-602).

Objectives of the Study :

- To explore how social media is affecting linguistic habits of Millennial 
- To examine the impact of social media on the orthography, typography and grammar of English language

- To explore the measure to protect the linguistic habits of millennial from the negative influence of social media

Methodology and procedure

Participants

The researcher has randomly selected 61 participants from Aligarh Muslim University of Aligarh, India and has analyzed their social media posts (include public and private posts, comments and statuses). Not all the social media platforms are considered here for the study; only the corpus from Facebook, WhatsApp and Instagram application are scrutinized in this study. These participants belong to 18-35 years age group (i.e. millennial age group). All of them are engaged in academic line (out of 61 Research participants, 23 were pursuing graduation, 25 post graduation and 13 were engaged in research).

Procedure

First, with the permission of research participants, the raw chats, posts, comments, statuses of research participants were seen. They were informed one week before about the study. This was done by sending them the tentative synopsis of the study and invitation for the meeting. So, at the time of meeting they were ready with the chats they want to contribute toward the completion of the study. Four meetings were arranged of two hours respectively and in every meeting 30 minutes were given for discussion. The meeting was categorized according to the academic level of research participants. First meeting consisted of twentythree Graduates, Second meeting twenty-five post-graduates and third consisted of thirteen Research scholars and fourth meeting was devoted for discussion and wind-up session. Four participants (two graduates, one post-graduates and one research scholar) were unable to make 
it up to meeting. So they were asked to export the chats, post, statuses and comments through email.

The corpus was collected using the screenshot feature of the smart phone. Screenshots were taken of the chats, post, comments and statuses and participants were asked to transfer the screenshots to the pen drive provided to them. After the collection of screenshots, research participants were asked the reasons behind the use of textism in conversation and they stated various reasons for defying of English orthographic and typographic norms on social media platforms. These were then classified by the researcher into eight categories (see Discussion section).

There were total one hundred and thirty-two raw screenshots and out of them, onehundred and twenty-seven screenshots were chosen on the basis of the textism found in them and the other parameter for the selection was number of words and the content (see Parameters for data collection Section). There are twenty-one types of textism discussed by the researcher in the research paper. Then the next task was to hide the identity of the screenshots and mark the textese in those screenshots. This was done with help of Paint tool programme of Microsoft Window. Using the Microsoft Excel Sheet, the data was stored and analyzed and graphical summary was prepared.

Parameters for data collection

- The researcher has collected the data by personally meeting and interviewing the participants. With the permission of the participants their conversations, comments, statuses, and posts were seen, captured and analyzed. They were captured with the help of screenshot and later analyzed by the researcher.

- There were total sixty-one research participants included in this study. Of which twenty three are doing graduation, twenty-five are doing post graduation and remaining fifteen participants are engaged in Ph.D. 
- Out of sixty-one participants, four participants were not able to meet personally, so the researcher corresponded with them on WhatsApp program and asked them to export those chats which they feel comfortable in sharing with the researcher through email. WhatsApp has the feature of exporting the chat, through this feature whole chat gets exported through email and other sharing apps. Since these chats were raw and contained unnecessary data too, whole chats are not analyzed by the researcher. Researcher has selected the required corpuses from them and then done the analysis.

- The raw data (here it is in the form of chats, posts, statuses and comments) consisted the conversations that are done both in Hindi and English languages. The conversations that are done solely in English are considered for the study and the conversations that are done mainly in English and having minor part or fillers in Hindi are also considered for the study.

- The whole conversation is not selected for analysis. Just the part of the conversation is taken for analysis. That is, from where the topic/discussion is triggered (minimum four dialogues consisting of 38 words).

Regarding the ethics of research, the researcher has candidly talked about the whole programme that is, why the chats are required, what will be done with the screenshots of those chats and the researcher had convinced the participants that the data will solely be used for research purpose and assured the participants regarding the privacy of their conversations and their identities. Thereby, maintaining the ethics of research. In addition to this, researcher has completely hid the identity of the chats using the paint tool application.

Findings

The analysis of the data collected from the research participants unfolds the significant characteristics of participants' linguistic habits i.e. how social media has affected their 
linguistic habit. "The flouting of orthographic and typographic norms and linguistic and typographic playfulness are evident" (Danet and Herring 2007:12) in the collected data. They have frequently used the following "non-standard typographic and orthographic forms" (Thurlow 2013:6). The researcher has made twenty-one categories in order to highlight textism in the collected data. It is unfeasible to include all the screenshots of collected data here. Thus, small glimpse of collected data is provided (see Appendix 2):

1. Coining: Invention of new words which do not exist in English language. Data consists of words like: 'photobombing', 'unfriending', 'googling', 'whatsapping', 'facebooking'.

2. Initialism: First letters of each word in a compound word, phrase, and sentence are put together. The data shows number of initialism in the participants' conversation. They are 'Ttyl', 'lol', 'bff', 'Imao', 'AFAIK' - 'As Far As I Know', 'BAE'- 'Before Anyone Else', ‘brb'- 'Be right back', 'FYI' - 'For Your Information', 'OOTD'- 'Outfit Of The Day', 'OMW' - 'on my way', 'POTD'- 'Photo Of The Day', 'TBH' - 'To be honest'.

3. Contraction: Shortening the word by deleting letters, usually letters that have vowel sounds are deleted. In some cases, participants have not just deleted vowels but also words and phrase. The participants have made use of words like ' $k n w$ '- 'know', 'cn''can', 'wat'- what, 'wl'- 'will', 'bt'- 'but', 'ur'- 'your', 'coz'- 'because', 'gonna''going to', 'lemme'- 'let me', 'kinda'- 'kind of', ‘dunno'- 'don't know', 'gotcha'- 'got you', 'gimme'- 'give me', 'c'mon'- 'come on', 'z'- 'is', 'm'- 'I am'.

4. Clipping: Clipping is when the front, back and both front-back parts are omitted and remaining part of word is left retaining the meaning of original word. The data has many clipped words, they are 'lib'- 'library', 'Eng'- 'English', 'em'- 'them', 'Alig''Aligarh', 'alrigh'- 'alright', 'info.' - 'information' etc. 
5. Phonetic Respelling: "substitution of letter(s) of word by (an) other letter(s), while applying accurate grapheme-phoneme patterns of the standard language" (Verheijen and Stoop 2016: 255). Phonetic respelling is frequently done by the participants in their personal messages. Here are some words that depict this feature: 'ur'- 'your', 'wl''will', 'mmbrz' - 'members', 'olryt' - 'alright', 'thru'- 'through', 'hlp' - 'help', ' $d$ '- 'the', 'm'- 'am', 'ppl' - 'people', 'ekzactly'- 'exactly', 'nyt' - 'night', 'aftanoon'- 'afternoon', 'asignmnt'- 'assignment', 'Wwl' - 'We will'

6. Number Homophone: "A number used to replace a word or part of a word which has the same pronunciation”' (Kelsey and Amant 2008: 933). '4get'- 'forget', '9t'- 'night', 'b4'- 'before', 'w8'- 'wait', 'w8ng'- 'waiting', '2day'- 'today', 'g8'- 'great', 'evryl''everyone'.

7. Reduplication: Repetition of letter(s). Participants have used 'soooo'- 'so', 'longgg''long', 'happyyy'- 'happy', 'okayyy'- 'ok', 'byeeee'- 'bye', 'finallyyyy'- 'finally', 'yess'- 'yes', ‘helloooo'- 'hello', 'heyyyyy'- 'hey', 'waitinggg'- 'waiting'.

8. Use of visual in spelling: Substitution of letter(s) by graphically resembling nonalphabetic symbol(s), e.g. ‘@mna'-‘Amna', ‘pool’-‘pool’, ‘\$h@ke’-‘shake’

9. Absurdity: 'laterz'- 'later', 'bcozz'- 'because', 'Lx'- 'linguistic'

10. Accenting: 'Ohhkayy'- 'okay', 'Hallo'- 'Hello', 'Frandz'- 'Friends'

11. Missing diacritics: 'nä̈ve'- 'naïve', 'café'- 'Café', 'doppelganger'- 'Doppelgänger', 'resume'- 'résumé', ‘uber'- 'über'.

12. Reduplicating symbols: Repeating punctuation symbols. Participants have used (...) after completion of the each sentences of the paragraph. Even if they have written one sentence, there also they have used row of full stop. For expressing mood they have used row of exclamation mark (!!!) and for asking question for which they need urgent reply, they have chosen this (????). 
13. Relaxation in Capitalization: Participants have used capitalization in the following way like: 'Itz MINE'- 'mine', 'OKAY' - 'Okay', HaPpY' - 'HAPPY' which are deviant from the English language norms.

14. Use of emoji: Emojis are very commonly used by the participants. For expressing what they exactly want to say, participants have used them. Apart from this they have used them, in the case where they do not want to reply or do not want to type any further. So they have simply put the emoticon instead of typing feelings in words. Here are few of them:

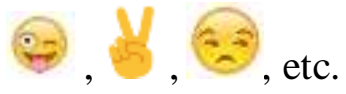

15. Use of Hashtag: A word or phrase preceded by a hash sign (\#), used on social media websites and applications, especially Twitter, to identify messages on a specific topic ("hashtag" 2019). Apart from its original use (i.e. to identify message on a specific topic), it is used to state in short what you want to convey. Participants have greatly used hashtags not only on twitter but also in other social media sites. As through the hashtag, one can describe in few striking words the whole story without the use of complete grammatical sentences. \#BookingOpenForZero (indicates be ready to watch this movie and the participant who has used this hashtag is excited and informing and inviting his other friends.), \#OOTD (the participant has not mentioned any occasion and other detail; just informing other that she has worn this beautiful dress today and expecting her friends' reactions).

16. Memes: "An image or video that is spread widely on the internet, often altered by internet users for humorous effect" (“Definition” 2019). In interview, when participants were asked why they use memes they stated the following reasons: in order to save their time from typing; for humorous purpose; it is a catching way for expressing your feelings and it is in trend; sometimes they do not understand what to reply so they use 
memes; sometimes they know what to say but do not know how to say, so they use meme to express themselves; when in hurry, etc.

17. Use of words from mother tongue: Mother tongue is commonly use along with the English language. Whether WhatsApp, Facebook, Instagram messages or public comments, posts on WhatsApp, Facebook, Instagram, Twitter' sites, mother tongue interference can be widely seen in the data. 'And then wahan se we have to go to Srinagar', 'Arey Haan, I had a look', 'Arey, they will charge us more', 'Usme they have asked outstation participants to share their travelling information', 'Another issue is $k$ my number won't work there'. These italicize words are from the Hindi language. Participants have used them many times in their conversation.

18. Relaxing of grammatical and punctuation rules: Grammatical rules relaxation can easily be seen in their comments, posts, etc. they have commented for the sake of communicating their ideas and have modified the standard norms of English language.

19. Slang: "unconventional words or phrases that express either something new or something old in a new way... Slang emanates from conflicts in values, sometimes superficial, often fundamental. When an individual applies language in a new way to express hostility, ridicule, or contempt, often with sharp wit, he may be creating slang" (Maurer). Here are some slangs used by the participants: 'creep', 'Jerk', 'funky', 'Freak-out', 'Kudos', 'All right?', and 'not my cup of tea'.

20. Giphy: Giphy is small video without sound, highlighting particular emotion. Here is the glimpse of some giphy used by the participants:
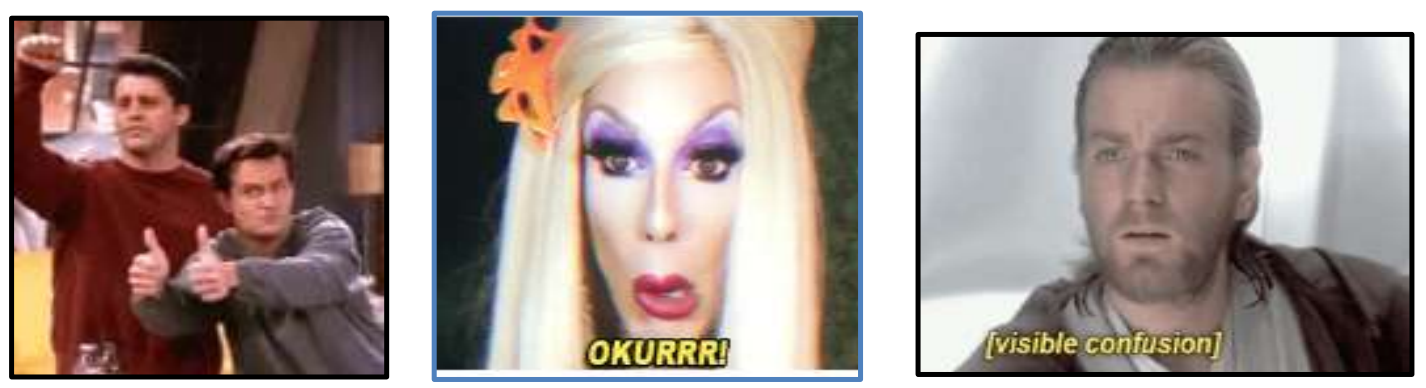
21. Stickers: "Stickers are different than emoticons. They're detailed illustrations of characters with personality. Sending stickers is a way to share how you're feeling with your friends" (Randall 2013). Participants have used them on various occasions like when appreciating friends' picture, when agreeing/disagreeing on any topic or when they do not want to do any further discussion on a topic which they feel being exaggerated by their friends in case too they just have inserted the sticker and have not replied further. So they have used stickers as an important tool for establishing, abandoning and continuing the conversation. Here are the glimpse of stickers:
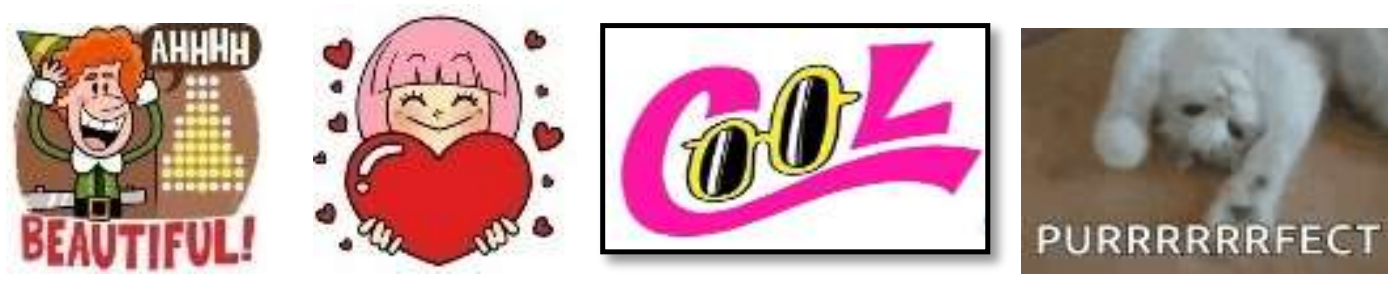

Here is the graphical representation of Textism found in the corpus collected from all research participants: 


\section{Textism found in data collected from Graduate research participants}

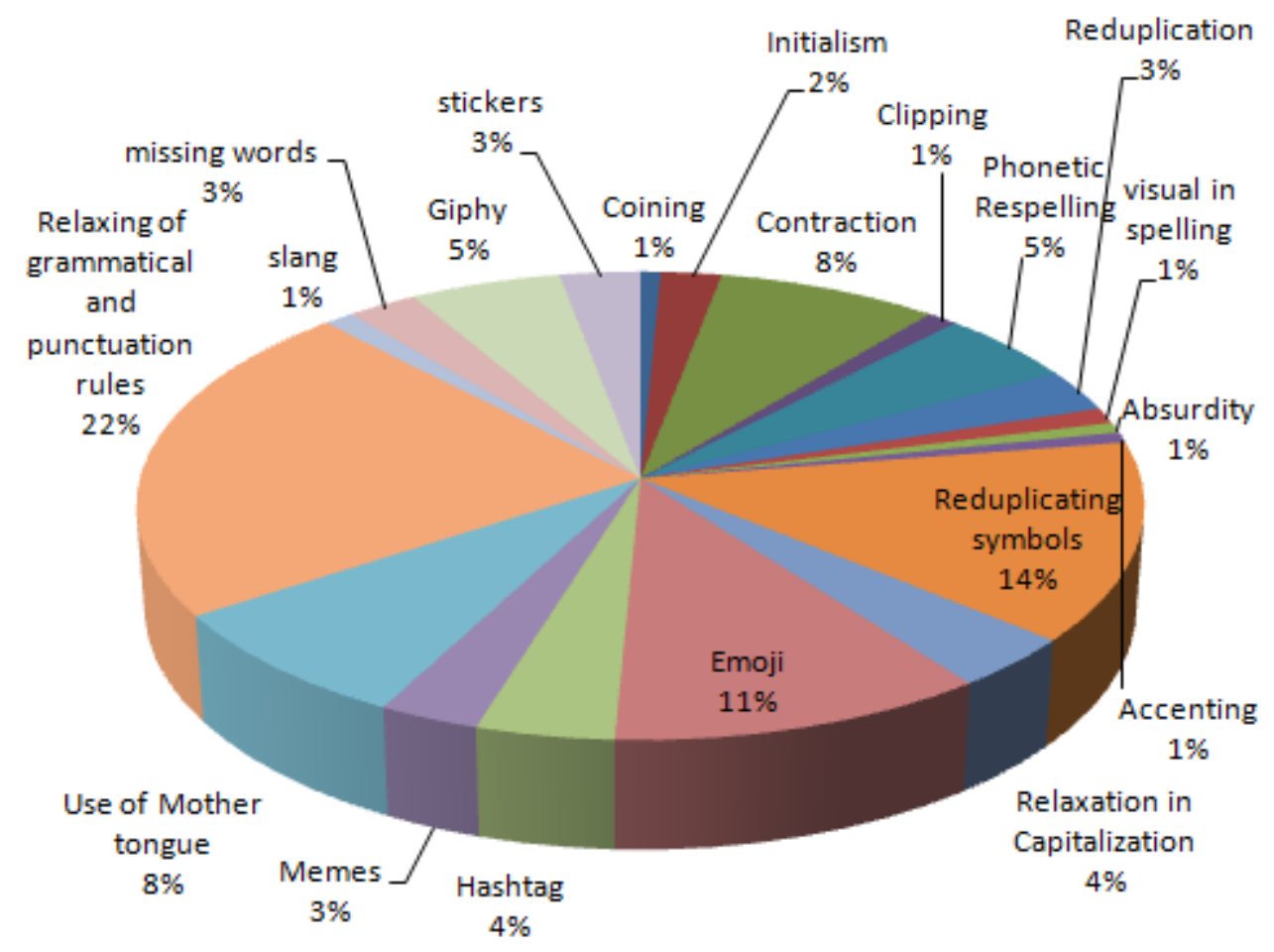

Figure 2: The graphical representation of the Textism found in data collected from Graduate research participants 


\section{Textism found in data collected from Post graduate research participants}

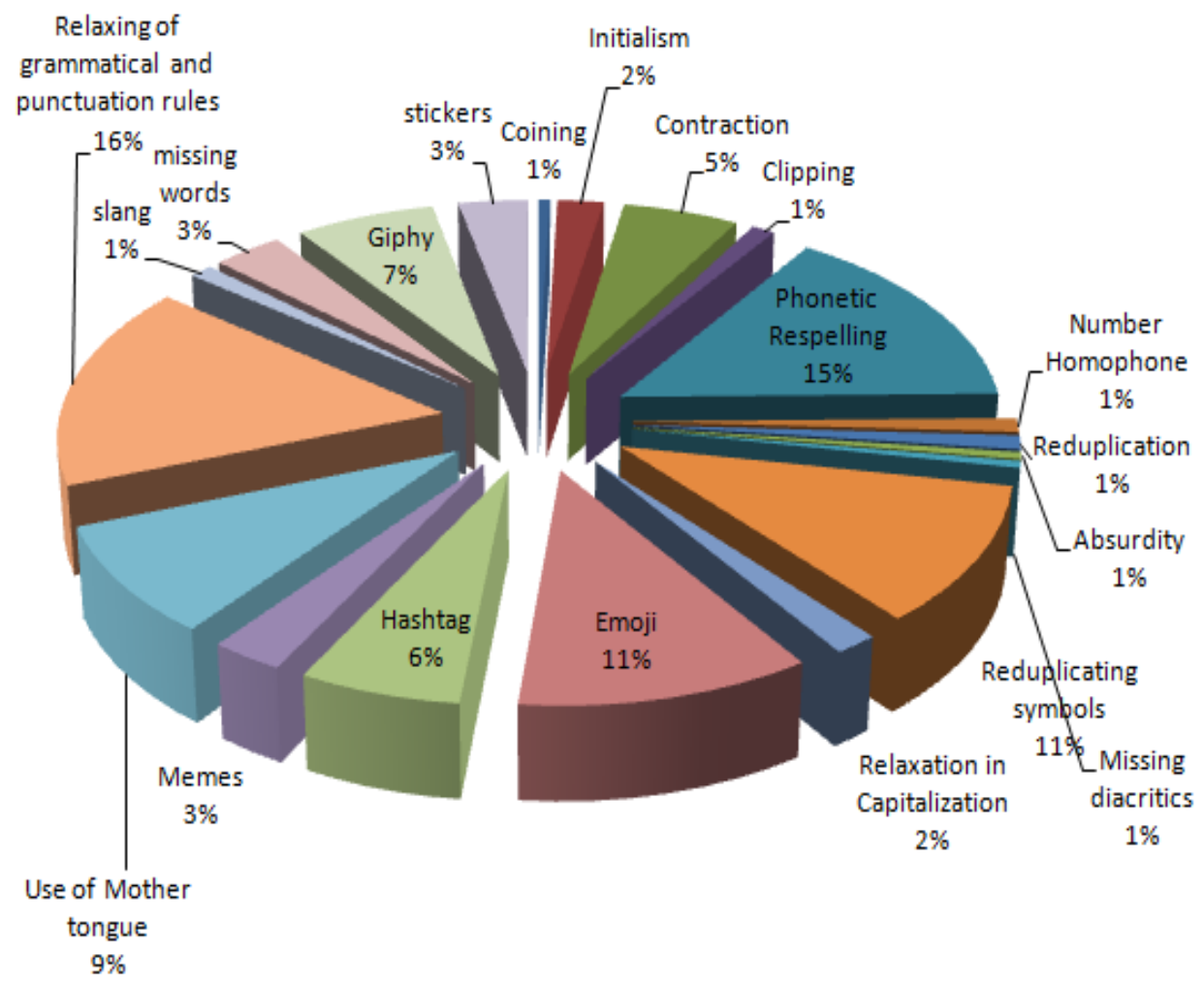

Figure 3: The graphical representation of the Textism found in data collected from Post-

Graduate research participants 


\section{Textism found in data collected from Ph.D scholar (research participants)}

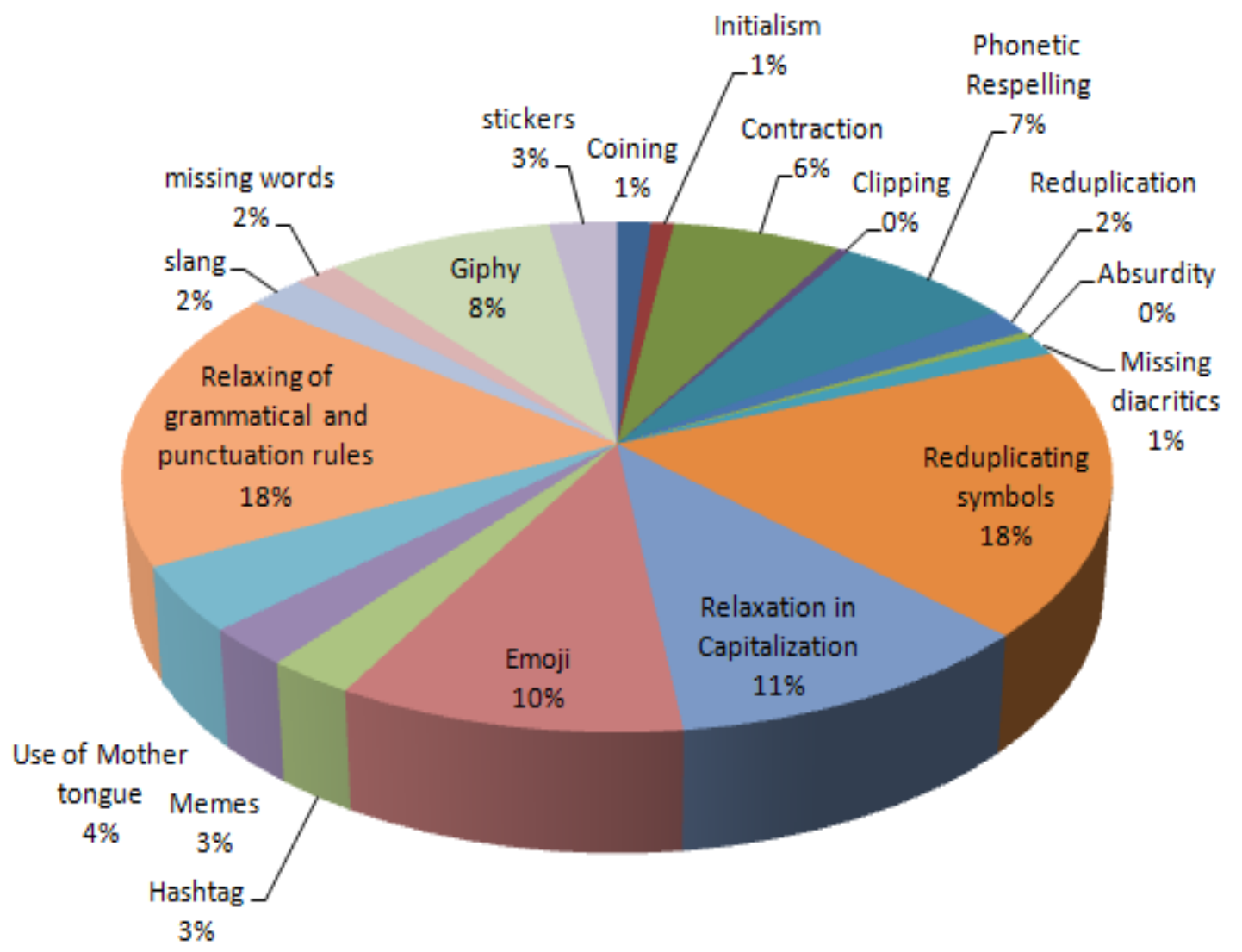

Figure 4: The graphical representation of the Textism found data collected from in $\mathrm{PhD}$ scholar (research participants) 


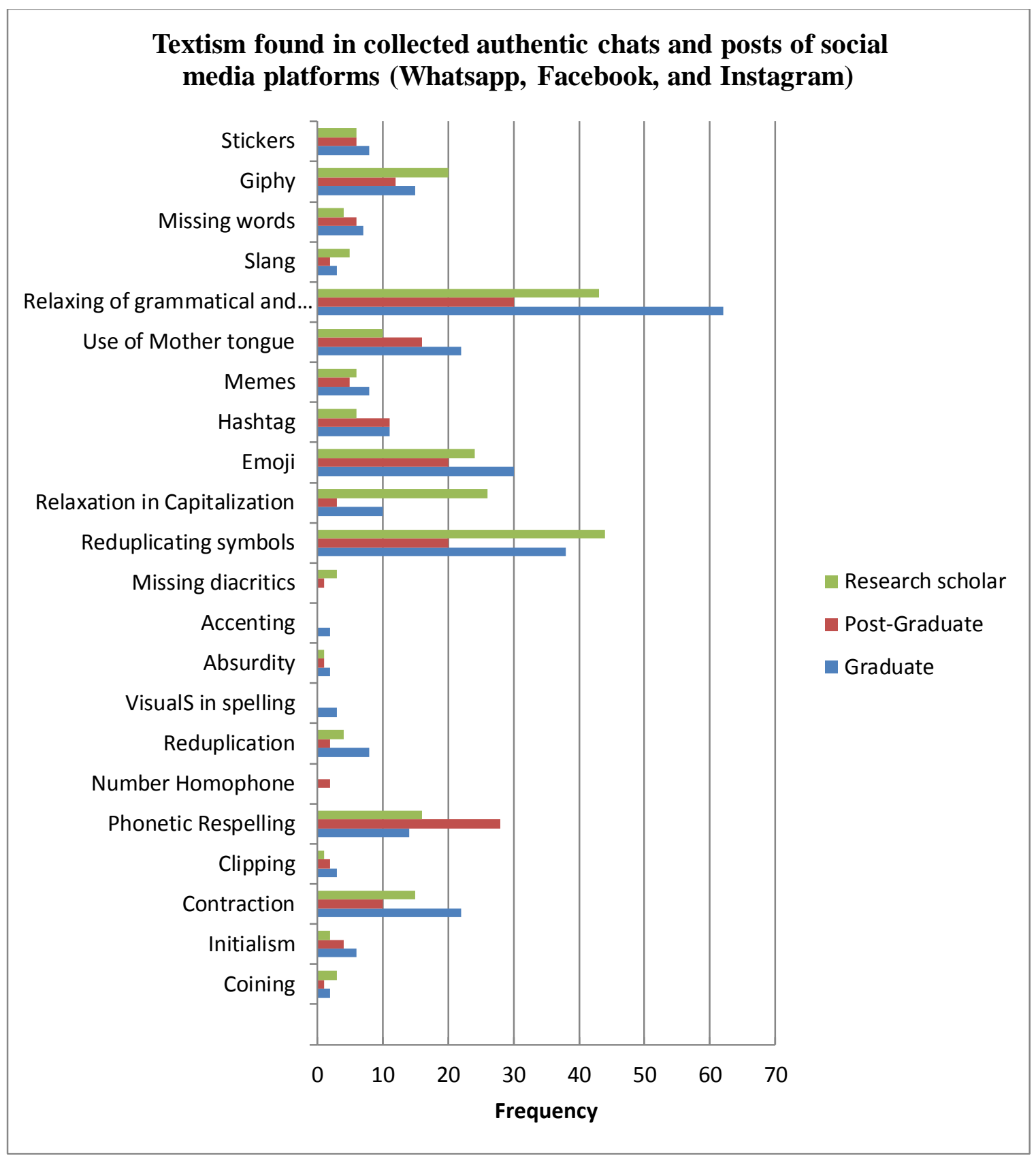

Figure 5: The graphical representation of the Textism found in collected authentic chats and posts of social media platforms (WhatsApp, Facebook, and Instagram).

Discussion

After analysis of the total collected data, it is clear that 'Relaxation of Grammatical and punctuation rules' is most common type of the textisim present in the authentic chats and post of social media platforms; with 22 percent in graduates, 16 percent in postgraduates and 18 percent in research scholars' corpuses. While 'reduplication of symbols' is seen as second most 
commonly found textism in the participants' corpus; with 14 percent in graduates, 11 percent in post graduates and 18 percent in research scholars' authentic chats and posts. 'Emoji' comes third with 11 percent found in graduates, 11 percent in post graduates and 10 percent in research scholars' collected data. Thereafter come other types of textism, below they are arranged according to their frequency of occurrence in total collected data:

- 'Phonetic respelling' with 5 percent in graduates, 15 percent in post graduates and 7 percent in research scholars' corpuses;

- 'Use of mother tongue' with 8 percent in graduates, 9 percent in post graduates and 4 percent in research scholars' corpuses;

- 'Contraction' and 'Giphy' with 8 and 5 percent in graduates, 5 and 7 percent in post graduates and 6 and 8 percent in research scholars' corpuses respectively;

- 'Relaxation in capitalization' with 4 in graduates, 2 in post graduates and 11 percent in research scholars' data;

- 'Hashtag' with 4 percent in graduates, 6 percent in post graduates and 3 percent in research scholars' corpuses;

- 'Stickers' and 'Memes' both with 3 percent in graduates, post graduates and research scholars' corpuses respectively presenting equal percent of textism;

- 'Missing words' with 3 percent in graduates, 3 in post graduates and 2 in research scholars' corpuses;

- 'Reduplication' with 3 percent in graduates 1 percent in post graduates and 2 in research scholars' corpuses;

- 'Initialism' with 2 in graduates, 2 in post graduates and 1 percent in research scholars' corpuses;

- 'Slang' with 1 percent in graduates, 1 in post graduates and 2 in research scholars' corpuses; 
- 'Coining' and 'Clipping' with 1 and 1 percent in graduates, 1 and 1 percent in post graduates and 1 and 0 percent in research scholars' corpuses respectively i.e. in research scholars' corpuses clipping is nil;

- 'Absurdity' and 'Missing diacritics' with 1 and 0 percent (i.e. missing diacritics is nil) in graduates, 1 and 1 in post graduates and 0 (i.e. absurdity is nil) and 1 percent in research scholars' corpuses respectively;

- 'Visuals in spelling' with 1 percent in graduates, 0 percent (i.e. Visuals in spelling is nil) in post graduates and 0 percent (i.e. Visuals in spelling is nil) in research scholars' corpuses;

- 'Number homophones' with 0 percent in graduates i.e. they are not used by graduates, 1 percent in post graduates and 0 percent i.e. number homophones are absent in research scholars' corpuses.

Language is the systematic medium of communication, which has evolved and adapted by the learner according to their needs. This evolution and adaptation of the language is happening since its genesis. Beowulf, Chaucer's Canterbury Tales, Shakespeare's unsurpassable writing are finest examples of how language has evolved and adapted systematically. From phonetics, phonology, morphology, syntax, semantics and pragmatics, every bit of language has gone through gradual modification. But the age of information and technology has brought rapid change in the way language is used. And this has given birth to non-standard typographic and orthographic form. These forms are being used ineptly thereby affecting the linguistic habit of the upcoming generation in unfavorable way. Many factors were unfolded after the discussion with the subjects and through the analysis of collected data, pertaining to the reasons behind the defying of English orthographic and typographic norms in social media platforms. Here are those factors: 
1. For bringing more emotion and effectiveness to the conversation

Research participants were of the view that by elongating the spelling of words (for examples: soooo, finallyyyy, yess, yasssss, waitinggg and so on), they are able to add more emotions to the word. Suppose the word 'finallyyy, for them this word is more expressive than the word 'finally'. Former word represents that after a very hard effort someone have reached or achieved something and one can imagine the emotion of the speaker or the sender, while later too represent the same, but with less effectiveness. Similarly the word 'Yesss' or 'Yasssss' for Yes'; 'Sooooooo' for 'so' and many more textism are seen in collected data.

\section{Lack of knowledge}

Because of lack of knowledge of grammatical structure, some participants were of the view that in order to avoid the grammatical mistake, they use this strategy of putting the concrete words together along with hashtags (for examples: \#BookingOpenForZero) for conveying the message. Instead of writing 'The ticket booking has started for the film Zero', they prefer to write in concise way (e.g. BookingOpenForZero, \#revokeSedition\#WeareAligs\#WeareONE, \#against\#every\#wrong) and this way does not require much knowledge of grammar.

\section{Laziness and Busy schedule}

Though technology has helped us in accomplishing various tasks swiftly, but it has turned us indolent too. Typing of complete sentence requires both mental and physical efforts. So just to avoid these efforts millennial make use of various tricks for short and snappy communication on social media for examples putting the content words together along with hashtag, use of typical abbreviation, and so on.

4. Attempting to save time

Busy schedule is also one of the reasons stated by the participants for the digression from the standard word formation and sentence construction. Therefore in order to reply quickly and effectively, they prefer to make use of compact spelling, memes, Gifs, etc. 


\section{Relationship status}

Sometimes, statuses of the relationships too lead to the use of non-standard orthographic and typographic form. Deviation in orthographic and typographic form and use of emoticons, Gifs, memes are done mostly in informal context and conversation (conversation with friends, family and colleagues). As these contexts are more relaxed and use of these deviations often involve people that we know on a more personal level. In addition to this, social media platform has enabled one to form friends from distance and because of which now people have at least 200 friends on Facebook, 100 followers on Instagram and similar numbers on other social media handle. This has lead to the increase in communication. Therefore the responsibility on the shoulder of the person is increased now. Earlier he/she has to reply to four-five friends now he/she has to reply to so many friends available on different platforms of social media.

6. To flaunt

The deviation in words spelling and sentence construction are blazing a trail nowadays. Participants have expressed that the social media platform provides freedom, there is no restriction while doing deviation and moreover this deviation are setting trend. So they too prefer to do alteration and plunge into this trend.

\section{To gain Attention}

For some participants, deviation in word and sentence constructions, use of Gifs, use of emoticons, etc. catch more attention than the message typed in simple way.

8. No correspondence between letter and sound

Since there is no correspondence between letters of the alphabet and sounds they stand for, some participants were of the views that sometimes they are not able to recall the right spelling of the word they want to type; so according to how the word sounds, they form its spelling. For example one participant has used 'asgnmnt' for 'assignment', 'cruz' for 'cruise'. 


\section{Recommendations}

Language learning is a process of habit formation. The more often something is repeated, the stronger the habit and greater the learning (Bell 2016). Consequently, when we use deviant form of language repeatedly, this will soon become our habit and we will continue to use these forms everywhere irrespective of the context. On social media platform this deviation does not affect much but in terms of academics this new language poses a threat. This newly formed language of social media is the combination of non-standard orthography, typography, weird memes, Gifs, and emoticons. This language is not formed on the basis of some norms and conventions. People are using and learning social media language from the posts of adept users of the social media and then start using and applying this deviant language accordingly. From phonetics to Pragmatics, this new language is not formed on any rules and convention. It is just the uncertain modification which social media users made in the standard norms of English language according to their use and needs. It is not like, that the social media has only affected language in bad way, it has some positive impact too, like: it enables one to express freely without thinking much about conventions of the language, provides platform to put one's views, enables one to put one's opinion on public platform, gives opportunity to the language nerds to experiments with language by posting poems, stories, articles, etc. on social media platforms and some more.

So it is recommended that one should not completely discard the standard orthography and typography of English language while communicating on social media platforms and should try not to let the use of deviant form of language to become your linguistics habits. This can be done by listening, speaking, reading and writing of good academics and non-academics audios, videos and books respectively.

Millennial should try to make use of standard conventions of English language as much as possible in their posts. This will not only help them to upgrade their writing skills but through 
this they will inspire and help other to make use of appropriate and intelligible language in their writing of social media posts and comments.

Since the social media has become the need nowadays, it is difficult to completely abolish its negative effects. So one thing can be done, that is, use it intelligently. In a nutshell, use it not just for the sake of doing communication but also for making the conversation commendable, fathomable and acceptable globally.

\section{Conclusion}

From the interviews and data collected in this study, it is clear that the main reason behind the use of these deviant form of English language is to express oneself and what you are feeling (i.e. communication) effectively. On social media platform this deviation does not affect much but in terms of academics this new language poses a threat. Participants have blurred the conventional English language norms in quest of being more social and intimate. These deviant forms when used frequently will become part of our linguistic habits. It is concluded that, though social media has given us medium to express ourselves through various ways like deviant spelling of words, deviant grammatical structures, memes, hashtags, emoticons, etc. but one should try best not to make this deviant form of language as part of his/her linguistic habits because this habit will interfere in their academic studies and create hurdles in the accomplishment of language skills. 


\section{References}

Bell, Prudence. "The Audio-Lingual Method”, 2016, SlidePlayer, slideplayer.com/slide/9687016/ (accessed 10 March 2019)

Danet, Brenda and Susan C. Herring. "Introduction: Welcome to the Multilingual Internet", The Multilingual Internet: Language, Culture and Communication Online, 2007, p. 12, www.ut.edu.sa/documents/182223/5072461/The+Multilingual+Internet+Language,+Culture,+and+Communication+Online.pdf/286f20b9-6fec-4961-ad64$472 \mathrm{e} 8 \mathrm{~d} 721089$

"Definition of 'meme", 2019, Collins, www.collinsdictionary.com/dictionary/english/meme (accessed 30 September 2019)

Clement, J. "Instagram - Statistics \& Facts”, Statista, 14 May 2020, https://www.statista.com/topics/1882/instagram/

---. “Tumblr - Statistics \& Facts”, 20 August 2019, Statista, https://www.statista.com/topics/2463/tumblr/

---. "WhatsApp - Statistics \& Facts", 18 September, 2019, Statista, www.statista.com/topics/2018/whatsapp/

--.. "hashtag", 2019, English Oxford Living Dictionaries, en.oxforddictionaries.com/definition/hashtag

Jagtap, Urmila L. and Surekha R. Khare, "Use of Social Media in AIT Library: A Study", International Conference on Digital Libraries 2013, Vision 2020: Looking Back 10 years and Forging New Frontiers, edited by Shantanu Ganguly and P. K. Bhattacharya, TERI press, 2013, pp. 1060-1.

Kelsey, Sigrid and Kirk St. Amant. "Handbook of Research on Computer Mediated Communication", volume I, p. 933, 2008, Google Books, https://books.google.co.in/books?isbn=1599048647 
Maurer, D.W. "Slang: Linguistics", Encyclopedia Britannica, https://www.britannica.com/topic/slang

Ormerod, Katherine. "Introduction”, Why Social Media is Ruining Your Life, 2018, Google Books, books.google.co.in/books?isbn=1788401409

Pencak, Silvia. “Top 50+ Social Media Quotes”, 2019, PLC, silviapencak.com/top-50-socialmedia-quotes/

Randall, Angela. "Facebook Chat Stickers: What Are They and Should You Use Them? [Weekly Facebook Tips]”, 23 July 2013, MUO, www.makeuseof.com/tag/usingfacebook-chat-stickers-vs-emoticons-weekly-facebook-tips/

"Social Media", 2019, Techopedia, www.techopedia.com/definition/4837/social-media

Spencer, Jamie. “60+ Social Networking Sites You Need to Know About in 2018”, make website.com, makeawebsitehub.com/social-media-sites/

Tankovska, H. "Facebook - Statistics \& Facts", 5 February 2021, Statista, https://www.statista.com/topics/751/facebook/

---. "YouTube: Statistics \& Data", 19 February 2021, Statista, https://www.statista.com/topics/2019/youtube/

---. "Snapchat - Statistics \& Facts”, Statista, 19 February 2021, https://www.statista.com/topics/2882/snapchat/

---. “Twitter - Statistics \& Facts: Number of monetizable daily active Twitter users (mDAU) worldwide from 1 st quarter 2017 to 4th quarter 2020”, 22 February 2021, Statista, https://www.statista.com/statistics/970920/monetizable-daily-active-twitter-usersworldwide/

Thurlow, Crispin. "Generation Txt? The sociolinguistics of young people's text-messaging”, Jan 2013, p. 6, ResearchGate, 
www.researchgate.net/publication/259258527_Generation_Txt_The_sociolinguistics_ of_young_people's_text-messaging

Verheijen, Lieke. “The Effects of Text Messaging and Instant Messaging on Literacy”, 14 Jul 2013, p. 583, Taylor \& Francis Online, www.tandfonline.com/doi/pdf/10.1080/0013838X.2013.795737

Verheijen, Lieke and Wessel Stoop. "Collecting Facebook posts and WhatsApp chats:

Corpus compilation of private social media messages", Sep. 2016 p. 255, ResearchGate, www.researchgate.net/publication/307587308_Collecting_Facebook_posts_and_Wha tsApp_chats_Corpus_compilation_of_private_social_media_messages 
Appendix 1

\begin{tabular}{|c|c|c|c|c|}
\hline No. & $\begin{array}{l}\text { Designat } \\
\text { ion of } \\
\text { Participa } \\
\text { nts }\end{array}$ & $\begin{array}{l}\text { Total } \\
\text { number } \\
\text { of } \\
\text { participa } \\
\text { nts }\end{array}$ & $\begin{array}{l}\text { No. of personal conversation } \\
\text { screenshot collected (i.e. } \\
\text { *conversation with Friends, } \\
\text { Classmates and Relatives on } \\
\text { Whatsapp, Facebook and } \\
\text { Instagram) }\end{array}$ & $\begin{array}{l}\text { No. of public } \\
\text { conversation screenshot } \\
\text { collected (i.e. public } \\
\text { comments, statuses and } \\
\text { posts of Whatsapp, } \\
\text { Facebook and } \\
\text { Instagram) }\end{array}$ \\
\hline 1. & $\begin{array}{l}\text { Graduate } \\
\mathrm{s}\end{array}$ & 23 & $\begin{array}{l}\text { Total } 20 \text { screenshots } \\
\text { (of which } 9 \text { screenshots from } \\
\text { Whatsapp, } 6 \text { screenshots from } \\
\text { Facebook and } 5 \text { screenshots } \\
\text { from Instagram) }\end{array}$ & $\begin{array}{l}\text { Total } 30 \text { screenshots } \\
\text { (of which } 16 \text { screenshot } \\
\text { from Facebook } \\
\text { screenshots } 9 \\
\text { comments and } 7 \text { having } \\
\text { posts\}; } 8 \text { screenshots from } \\
\text { Instagram } 44 \text { screenshots } \\
\text { having posts and } 4 \text { having } \\
\text { statuses } \quad \text { and } 6 \\
\text { screenshots from } \\
\text { Whatsapp statuses) }\end{array}$ \\
\hline
\end{tabular}




\begin{tabular}{|c|c|c|c|c|}
\hline 2. & $\begin{array}{l}\text { Post } \\
\text { Graduate } \\
\text { S }\end{array}$ & 25 & $\begin{array}{l}\text { Total } 20 \text { screenshots } \\
\text { (of which } 8 \text { screenshots from } \\
\text { Whatsapp, } 6 \text { screenshots from } \\
\text { Facebook and } 6 \text { screenshots } \\
\text { from Instagram) }\end{array}$ & $\begin{array}{l}\text { Total } 32 \text { screenshots } \\
\text { (of which } 15 \text { screenshots } \\
\text { from Facebook } \\
\{7 \text { comments and } 8 \text { posts }\} \text {; } \\
8 \quad \text { screenshots from } \\
\text { Instagram }\{3 \text { statuses and } \\
3 \text { posts }\} ; 9 \text { screenshots } \\
\text { from Whatspp statuses) }\end{array}$ \\
\hline 3. & $\begin{array}{l}\text { Research } \\
\text { Scholars }\end{array}$ & 13 & $\begin{array}{l}\text { Total } 10 \text { screenshots } \\
\text { (of which } 5 \text { screenshots from } \\
\text { Whatsapp and } 5 \text { screenshots } \\
\text { from Facebook) }\end{array}$ & $\begin{array}{l}\text { Total } 15 \text { screenshots } \\
\text { (of which } 8 \text { screenshots } \\
\text { from facebook } \\
\text { \{comments and posts\}, } 3 \\
\text { screenshots } \\
\text { Instagram }\{\text { comments and } \\
\text { posts }\} \text { and } 4 \text { screenshots } \\
\text { from Whatsapp statuses) }\end{array}$ \\
\hline & $\begin{array}{l}\text { GRAND } \\
\text { TOTAL }\end{array}$ & 61 & 50 & 77 \\
\hline
\end{tabular}

* Conversation: With the permission of participants researcher has taken the screenshots of the conversations. The whole conversation is not selected for analysis. Just the part of the conversation is taken for analysis. That is, from where the topic is triggered, heart of the conversation, etc. (minimum four dialogues). 


\section{Appendix 2}

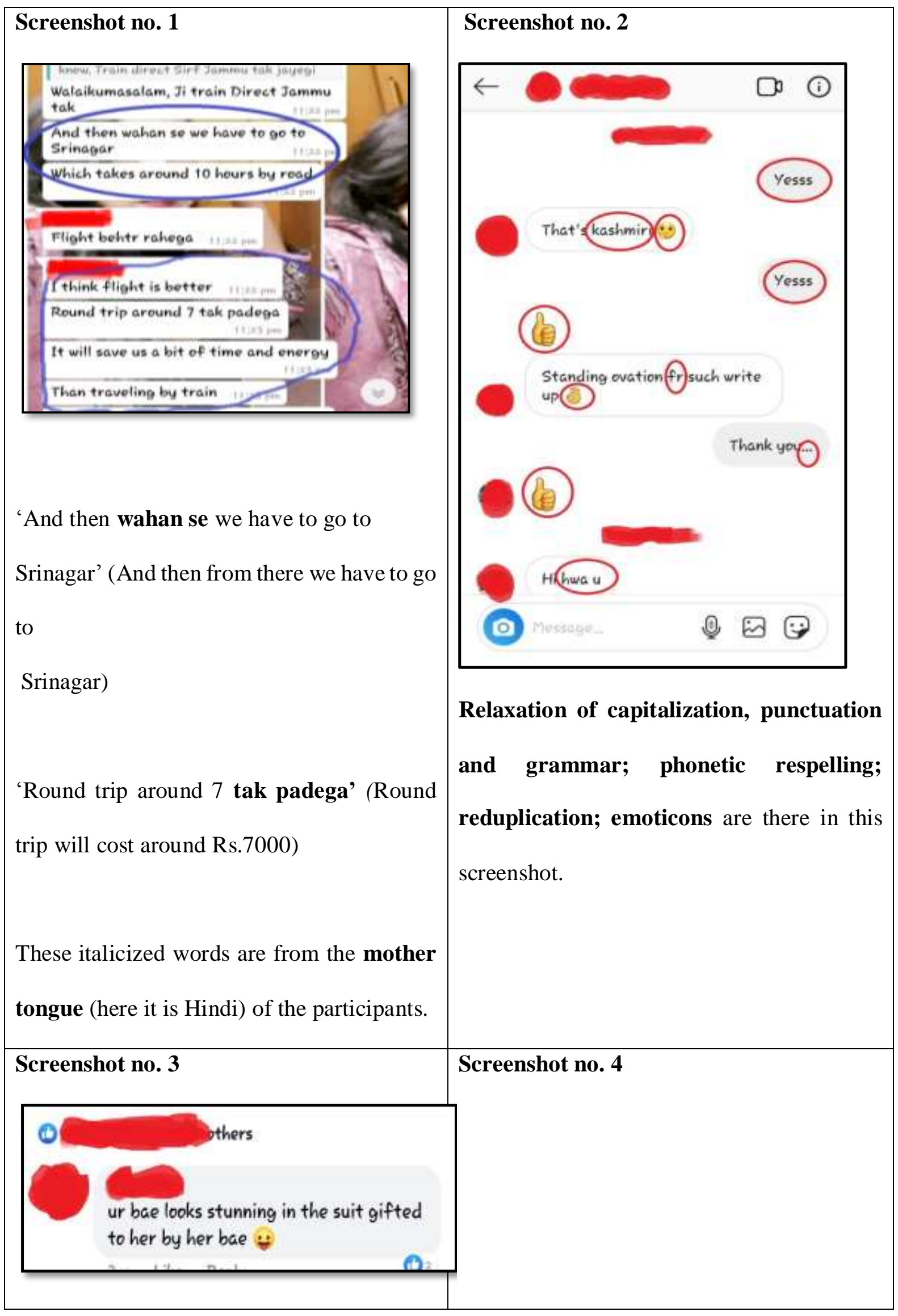




\begin{tabular}{|c|c|}
\hline $\begin{array}{l}\text { Participant has use Initialism in her text } \\
\text { message. She has use 'Bae' which is the }\end{array}$ & Wwl b there at library by $10 \quad 11: 34 \mathrm{pm}$ \\
\hline acronym for Before anyone else. & $\begin{array}{l}\text { Contraction can be seen here. Participant } \\
\text { has used 'Wwl b' for 'We will be'. }\end{array}$ \\
\hline Screenshot no. 5 & Screenshot no.6 \\
\hline $\begin{array}{l}\text { And empowerment here is a rusted } \\
\text { definition.. (1.) Why associate it with the } \\
\text { blessed upper hierarchy always, while } \\
\text { the same nation knows all the stories, } \\
\text { needless to say, how much an Indian } \\
\text { woman is empowered???? How much is } \\
\text { she respected?? How much undertone } \\
\text { remains hidden even in these celebrity } \\
\text { weddings??? } \\
\text { typical here... It's don't find anything } \\
\text { re-enforcing colonial comeback, } \\
\text { everything we fought for! }\end{array}$ & $\begin{array}{l}\text { \#researchpaper \# experiment \#blending \#poem } \\
\text { \#theroadnottaken \#technology\#tool\#audacity } \\
\text { \#software \#stress \#rhythm \#tone } \\
\text { \#CompulsoryEnglish\#class \#two \#days } \\
\text { \#wonderful \#teaching } \\
\text { \#experience\#alhamdulillah } 3 \\
\text { Special Thanks to My Bestiee G }\end{array}$ \\
\hline $\begin{array}{l}\text { Here participant has make use of } \\
\text { Reduplication of symbols (punctuation } \\
\text { marks). }\end{array}$ & $\begin{array}{l}\text { Here participants have explained the detail } \\
\text { of the day in concise way using Hashtag. }\end{array}$ \\
\hline Screenshot no. 7 & $\begin{array}{l}\text { Screenshot no.8 } \\
\begin{array}{l}\text { Ye mujhe samjh Ara h. Kindly present } \\
\text { urviews now }\end{array}\end{array}$ \\
\hline
\end{tabular}




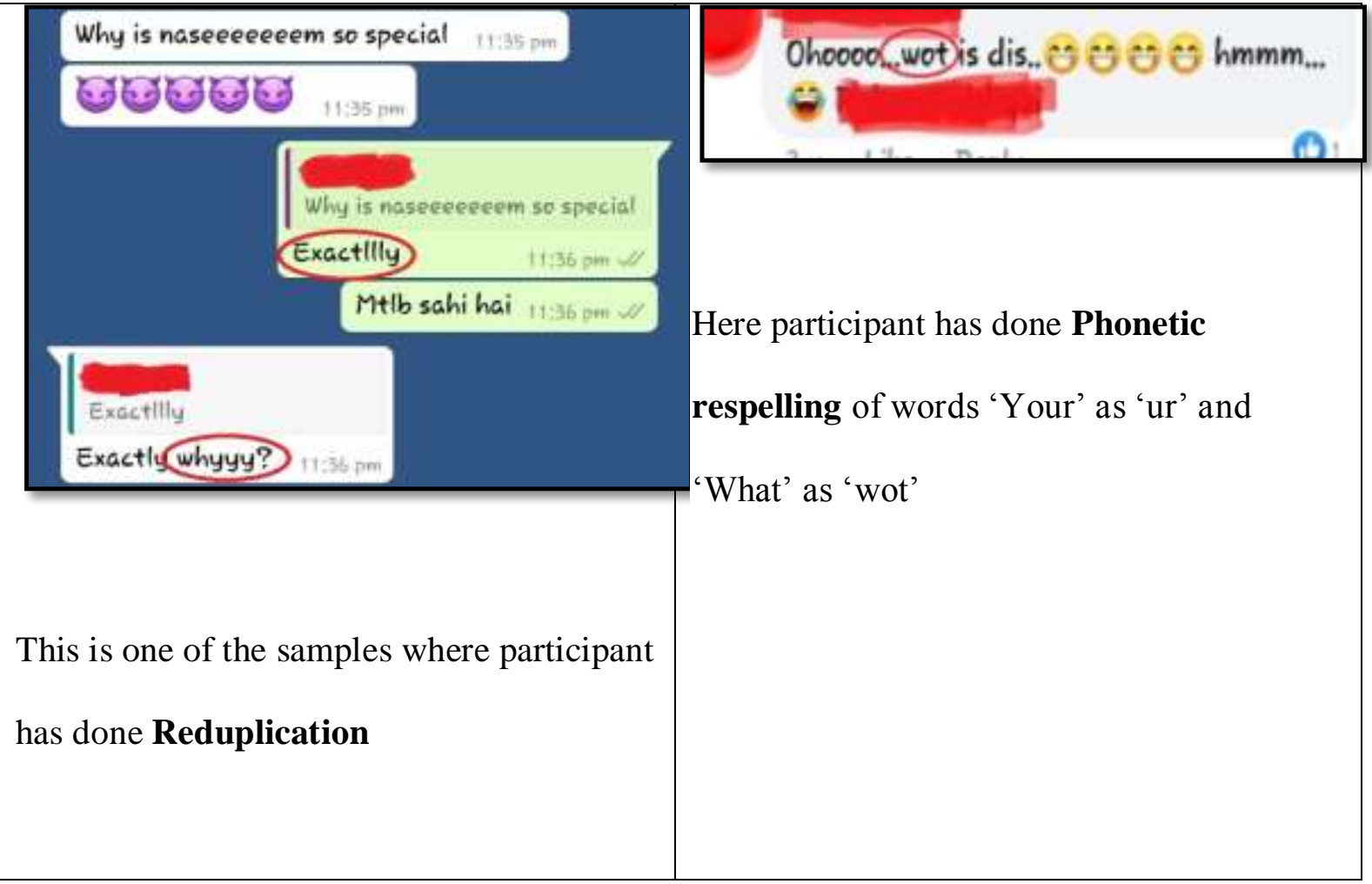

\begin{tabular}{|c|c|}
\hline Screenshot no. 9 & $\begin{array}{l}\text { Screenshot no. } 10 \\
\begin{array}{l}\text { Hallo frand2. made for each other jodi ko } \\
\text { dekhlo. }\end{array} \\
\text { Here participants has tried to Accent the } \\
\text { word by changing the vowel sounds of the } \\
\text { phrase 'Hello Friends' }\end{array}$ \\
\hline
\end{tabular}




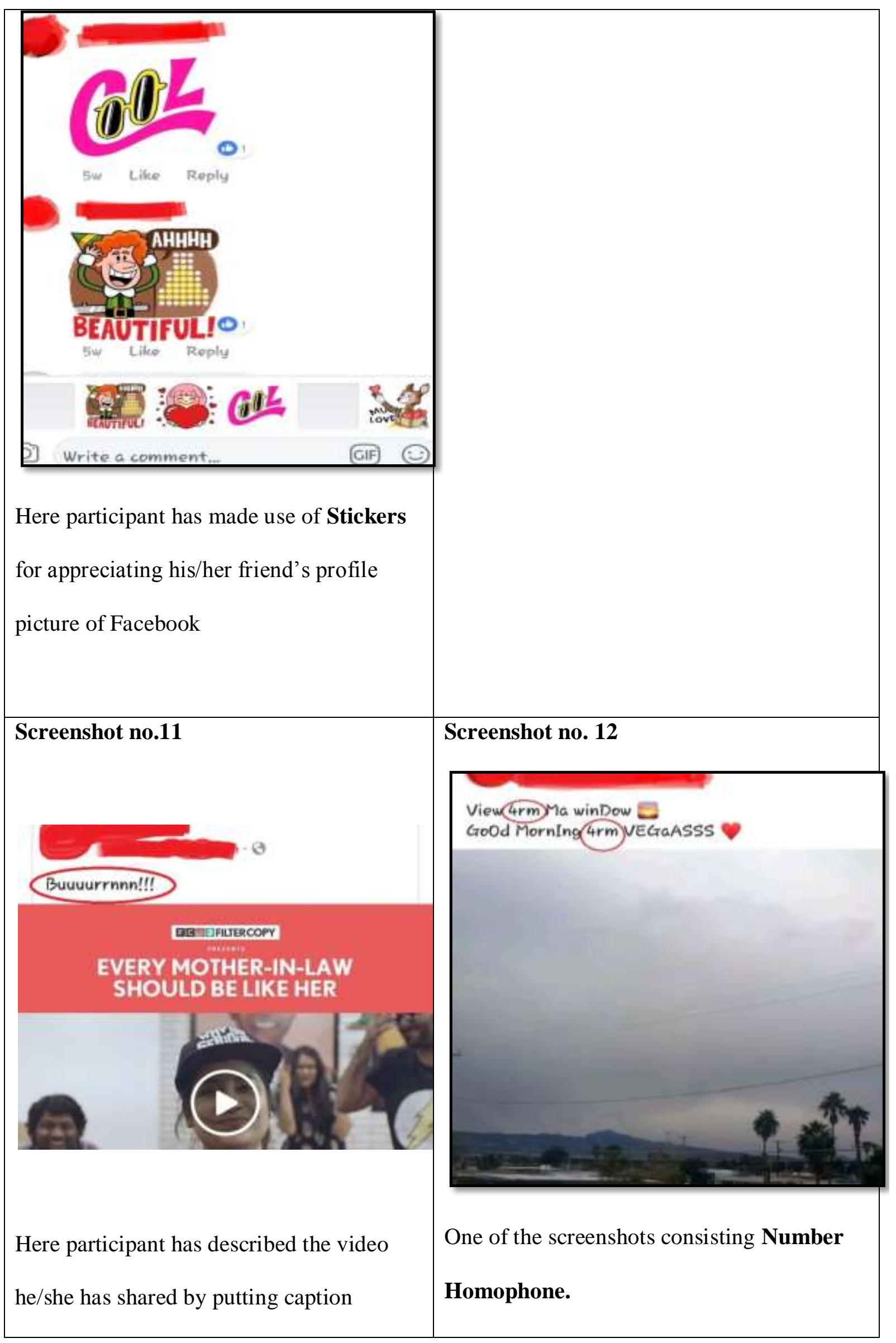




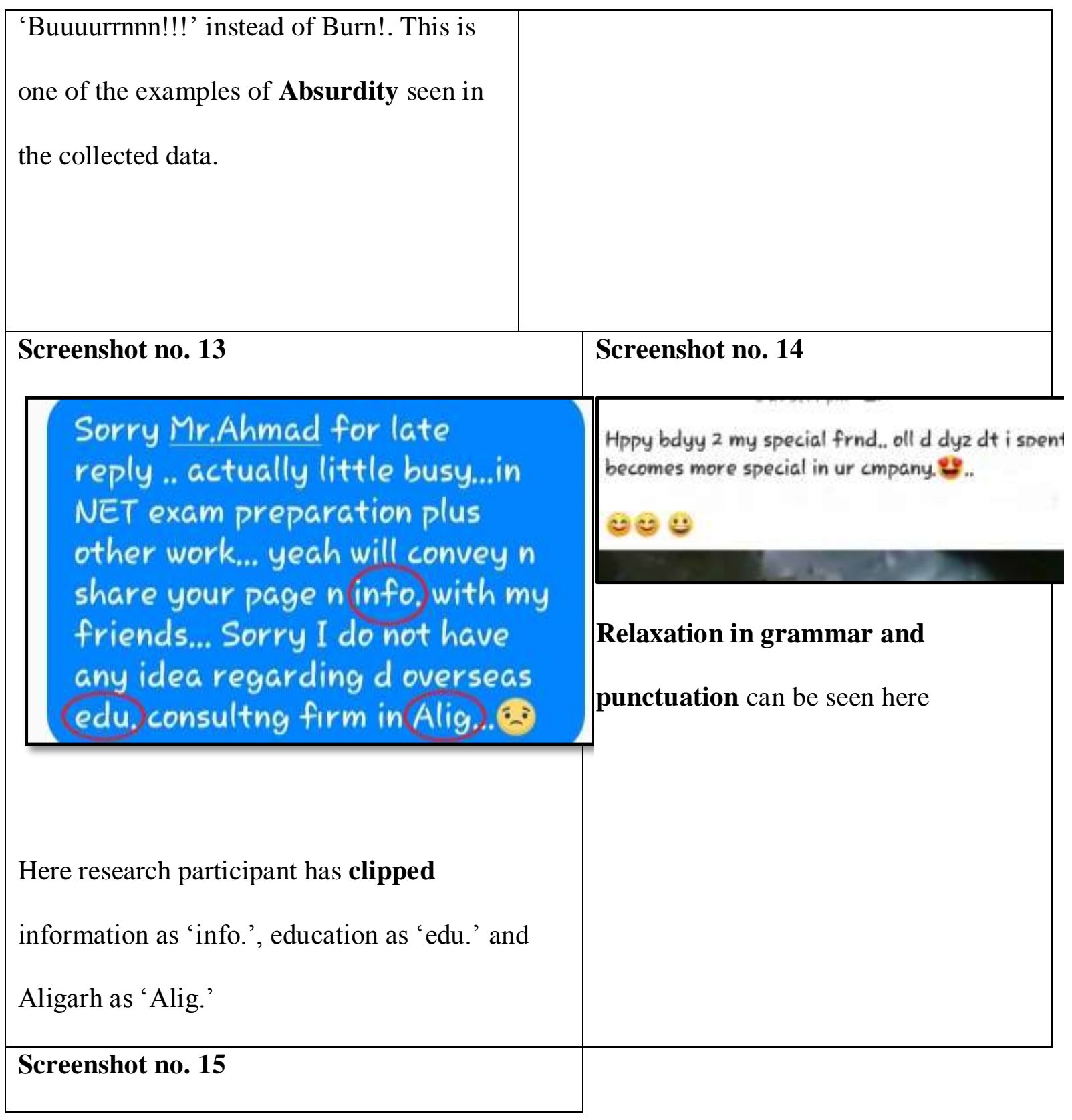




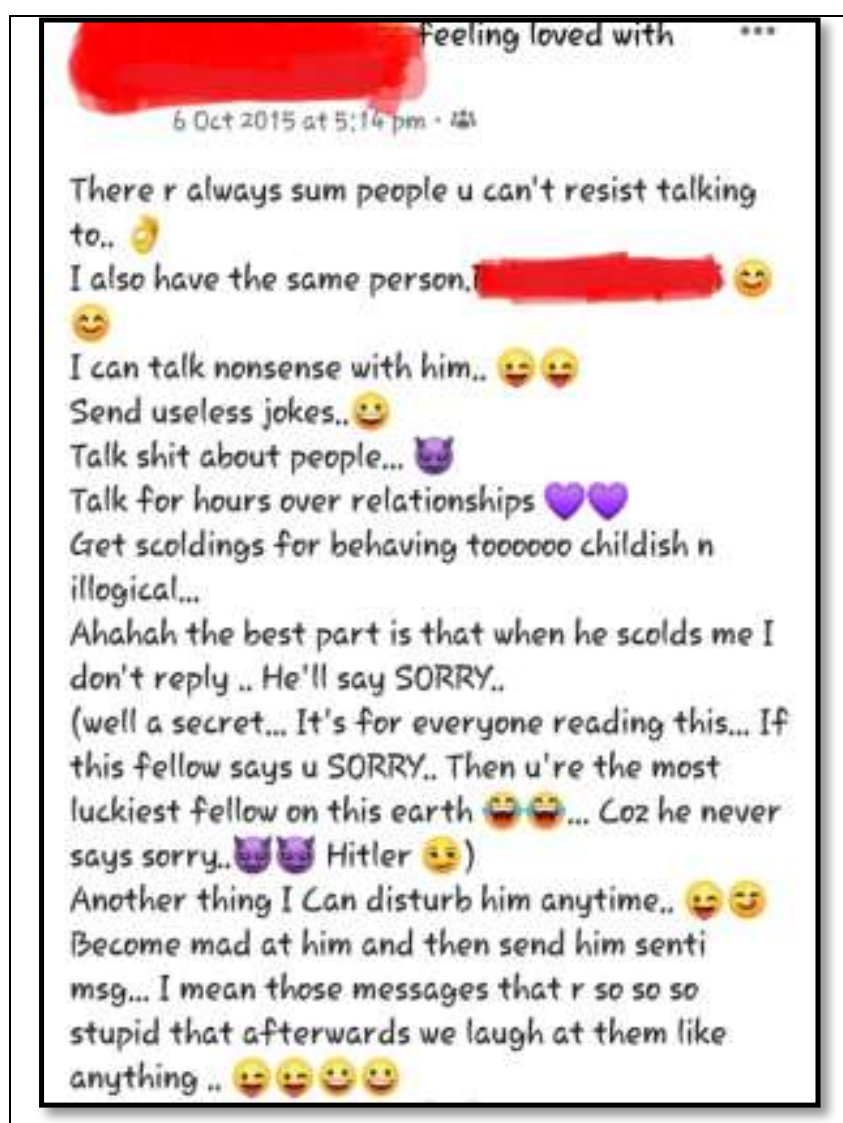

Here participant has used multiple emojis or emoticons; reduplication of symbols, letters; relaxation of capitalization, punctuation and grammar. 